\title{
SIGMUND FREUD - RETRATO DE UN ESCRITOR ${ }^{1}$
}

\author{
Walter Jens
}

\section{RESUMEN / ABSTRACT}

Partiendo de una conferencia de Wilhelm Stekel sobre el estreno de la obra de teatro 'Griselda' (1909) de Gerhard Hauptmann y la siguiente discusión en la llamada sociedad de los miércoles, se elabora la relación ambivalente de Freud con los poetas -como médico y como escritor.

Palabras clave: Psicoanálisis, literatura, historial clínico, creación literaria.

$$
\text { SIGMUND FREUD - PORTRAIT OF A WRITER }
$$

Based on a lecture by Wilhelm Stekel on the premiere of the play 'Griselda'(1909) by Gerhard Hauptmann and the following discussion in the so-called Wednesday society, Freud's ambivalent relationship to poets - as a doctor and as a writer-is elaborated.

KEYWORDS: Psychoanalysis, literature, case history, literary creation.

Recepción: 13/11/2020

Aprobación: 22/12/2020

El 31 de marzo 1909, un miércoles, en el domicilio de Sigmund Freud se reunió una sociedad integrada por siete caballeros (sus nombres: Federn, Hitschmann, Rank, Steiner, Sadger, Stekel, además del dueño de casa) para discutir, bajo la egida del conocedor del arte Rank, sobre un drama: Griselda de Gerhard Hauptmann, estrenado tres semanas atrás en el Burgtheater (junto a la Lessingbühne de Berlin) (cfr. Nunberg y Federn 166-174).

1 Traducción del alemán de Niklas Bornhauser. Publicación original: Jens, Walter (1991). Sigmund Freud - Porträt eines Schriftstellers. Psyche, 45(11): 949-966. 
Griseldis - Griselda: una Moritat de Boccaccio, que gracias a su despliegue de recursos psicológicos y su carácter abstruso en cuanto a lo anímico, podía estar segura de llamar la atención del círculo de los siete gentilhombres de la Sociedad Psicoanalítica de Viena. Un príncipe que -como personaje renacentista al modo de un berserker-doma a la muchacha salvaje proveniente del pueblo, en lugar de su oz le entrega un cetro, con tal de luego, lleno de envidia por la niña concebida por ambos, repudiarla brutalmente (el happy end se hace esperar). No ha de sorprender que semejante historia, con la naturaleza intrépida de Cesare Borgia y la mujer que oscila entre salvajismo y dulzura, haya desafiado tanto a la inteligencia como al ingenio del expositor y de los debatientes.

¡Qué pieza! ¡Qué oportunidad de presentar un ejercicio psicopatológico de altísimo nivel! Pero, por muy grande que haya sido la tarea -tan pobre parece, vista desde el presente, su superación. Stekel, que, con la mejor de las intenciones, quería defender la obra de Hauptmann contra cualquier crítica demasiado afectiva, aquí se conformó con caracterizar al protagonista como neurótico que -y en este lugar habría que dar la razón a la crítica- en tanto "festín para la medicina" (167) pertenece más bien a la Sorbonne que a una corte de nobles: un sádico y masoquista sería ese señor $-\mathrm{y}$, por supuesto, también su esposa, que después del casamiento experimentó una transformación en dama caritativa- una transformación que los señores críticos habrían expuesto como poco creíble; pero esto sería un error: uno bien podría considerarla válida "si se sopesa cuánto talento para encarnar una prostituta, una dama distinguida, para hacer de 'estimada señora' yace en toda mujer" (168)-, comenta Stekel; razón suficiente para proteger al poeta contra ataques descarados, aceptar el carácter sadomasoquista de ambos personajes principales como bien fundado psicológicamente y darle credibilidad a la antipatía, de parte del varón, hacia aquellas damas de la sociedad frente a las cuales él es impotente porque le evocan, por obra de magia, la imagen de la madre. ("Amó a la madre y odió al padre, y tomó conocimiento de este odio. En el niño ve sobrevenir la venganza del destino" (168f.)). Estos celos, así dice al final de su exposición, son "completamente justificados desde un punto de vista psicológico", al fin y al cabo el mismo Stekel "desde su consultorio estaba familiarizado con algunos casos de este tipo" (169).

Un hommage à Hauptmann entonces - simpático, si bien tosco: analizando la obra de arte de un creador literario mediante una nomenclatura rígida.

¿Una obra de arte? ¿Un creador literario? Ahí el valeroso Stekel se había dirigido al destinatario equivocado: Apenas había terminado el conferencista, 
como podemos suponer, el dueño de casa -lo que distaba de ser habitualtomó la palabra y se lanzó al ataque general contra Gerhart Hauptmann. Si bien recién había tomado conocimiento del drama a través de la mentada exposición, a pesar de su desconocimiento, podía afirmar que Hauptmann era un tipo "antipático" - un escritor de obras de teatro que, por lo visto, una vez más no había logrado exponer un tema de interés psicológico de una forma “capaz de cautivar y estimular" (169).

Freud no habría notado ni la menor señal de belleza poética: "El héroe es un perro loco que debe ser encerrado en un manicomio" (169), y en lo relativo al autor es patente que éste confundió al creador literario con un psicólogo -del tipo que a diario trata con problemas y se hace cargo de ellos terapéuticamente. El arte del escritor dramático, en cambio, explicaba Freud, apuntando a lo general, más allá del caso Hauptmann, y fundamentalmente desde un punto de vista poetológico, - el arte del creador literario consistiría, entonces, en "ganar un efecto poético de semejantes problemas y la experiencia nos muestra que estos problemas [...] tienen que estar disfrazados y que el efecto no sufre merma alguna si tan solo se intuyen los problemas y ninguno de los oyentes o lectores puede adquirir claridad en qué consiste el efecto [...] esencialmente en el encubrimiento" (169f.). Lo inconsciente solo debe ser consciente indirectamente, de manera insinuada -no debe ser iluminada explícitamente, en el acto de la transgresión de fronteras desde la poesía hacia una ciencia: "no es correcto de parte del creador literario", así el resultado y resumen freudiano, "poetizar nuestros análisis" (170)-y, para colmo, de manera tan diletante que una figura heroica, en contra de toda experiencia, por un lado es retratada como el hombre más viril y como sadista, y, por el otro, como debilucho neurótico. Demasiado esfuerzo, señor Hauptmann: "El hombre del teatro tiene que traer consigo una formación de carácter simple" (171), pero, al parecer, es justamente esa la que aquel poeta no poseía, que presumiblemente se había retratado a sí mismo en el debilucho caracterizado como sádico: un enano de Oberschreiberhau -podría decirse-medido en relación con un gigante como Ibsen, "con su carácter de cierre, unidad, simplificación de los problemas, con su arte de la concentración y del encubrimiento" que lo convertía en uno de los grandes de su gremio, "mientras que Hauptmann sería el neurótico que se retrata a sí mismo" (174).

¡Fuertes palabras!; de hecho, un asesinato en el ambiente analítico, ejecutado con rapidez y resuelto aún con mayor celeridad. Un consejo de guerra en la Berggasse, cuyo despreocupado procedimiento se muestra en el mismo instante en el que se compara la interpretación analítica con aquella 
interpretación ingeniosa publicada por Alfred Kerr el $1^{\circ}$ de abril, es decir, 24 horas después de la sesión de los siete hombres íntegros y erguidos: También aquí 'Griselda', también aquí la pregunta “¿Qué es un retrato del alma?”, también aquí el análisis psicológico de Ulrich von Saluzza (así el nombre del protagonista) -ipero con cuánta diferenciación, cuánto poder lingüístico, cuánto placer producto de la variación! El príncipe, un hombre loco de amor que se dirige a una criada, "porque está inseparablemente unido a estrellas, aires, noches, prados" y que valora más "las faldas ondeantes, los pechos ariscos, el pelo al aire" que al "anodino ambiente de invernadero, colmado de atenciones domésticas" y que con su "alma de papel de aluminio que se oculta detrás del cazador rudo" corteja a una muchacha, entre "asesinatos y risas", que es una mujerzuela campesina de elevada versatilidad y astucia: "Uno corteja con poder -y otra, procedente de profundidades terrenales, se familiariza con un mundo más filosófico".

Kerr contra Freud, el criticus profesional, por un lado, el médico diletante en el campo de lo poético, por el otro: esta es, así parece, una comparación poco adecuada, incluso injusta - ¿pero lo es realmente? Pienso que no: en cuanto uno considera que el crítico de Viena, tan despiadado como radical, un juez que sentencia según oídas, al mismo tiempo era un conocedor de la literatura y un poeta secreto que bien podía medirse en igualdad de condiciones con su antípoda berlinesa (al que no conocía y al que, en caso de que lo hubiera conocido, es probable que le hubiera tenido poca estima) en cuanto a introspección y fuerza lingüística. Si es que Freud atacaba a los creadores literarios, no lo hacía para destruirlos desde la posición del analista omnisapiente, sino porque los consideraba de los suyos -parientes cercanos a los que les leía un sermón en tono de reprimenda, porque se unía a ellos con la confianza que se tiene en un hijo, cuya intensidad se manifestaba no en última instancia en la articulación de decepciones: el gran Dostoievski, que con los Hermanos Karamasov, junto a Sófocles y Shakespeare, había escrito una de las tres grandes piezas sobre el parricidio... el gran Dostoievski -una figura moralmente ambigua, más Iván el terrible que un espíritu irenio, no un redentor de la humanidad, sino un traidor que hace causa común con los carceleros; no un reconciliador, sino una naturaleza dudosa que hoy derrama lágrimas sobre el estupro de pobres criaturas en todo el mundo y mañana, de manera servil, se somete al "zar y al dios cristiano".

En cuanto Freud se refería a los artistas, poetas y pintores, perdía toda soberanía y frialdad, abandonaba toda distancia y aquella neutralidad, propia del cirujano y del analista: tomaba partido, desechaba (infrecuentemente) 
y admiraba (con frecuencia); la resignación de cara al carácter romo de las herramientas con las que el psicoanálisis debía aproximarse a las obras de arte (lamentablemente, así Freud, el análisis tenía que rendir las armas ante el problema del artista), mantenía la balanza con aquella gran esperanza que, gracias a la descripción renovada de lo inconsciente de parte de Sigmund Freud y su escuela, al fin y al cabo sí sería posible obtener una mirada hacia el interior del centro de la manera poética de crear y de describir la actividad del alma de los artistas, en especial de los genios, en el límite de visión, creación y resultado: cuán cerca -esto lo deja en claro el discurso pronunciado en el Goethe-Haus en Frankfurt con motivo de la entrega del premio Goethe (¡la única distinción que Freud obtuvo en su larga vida fue de carácter literaria!)-, cuán cerca están la investigación del alma de los poetas, los enormes psicodramas de la literatura universal y aquel trabajo de por vida que realiza el analista, el cómplice de los soñadores diurnos de proveniencia poética que se habían fijado una sola meta:

Observé las más sutiles perturbaciones de la operación anímica en sanos y enfermos, y a partir de tales indicios quise descubrir -0 , si ustedes lo prefieren, colegir- cómo está construido el aparato que sirve a esas operaciones, así como las fuerzas que en él producen efectos conjugados o contrarios. Lo que nosotros, yo, mis amigos y colaboradores, pudimos aprender por ese camino nos pareció sustantivo para la edificación de una ciencia del alma que permita comprender los procesos normales y los patológicos como parte de un mismo acontecer natural (Freud 1930a, 208).

A diferencia de lo sucedido el año 1909, en 1930, un hombre ya viejo advierte no arrastrar a la creación literaria, como ocurrió en el caso 'Griselda', ante el tribunal del análisis (habiéndolo pesado y considerado demasiado liviano), sino, al revés, insta a obligar al arte científico del alma a justificarse ante la poesía y formular la pregunta de cómo se habría comportado él (Goethe: impreso en cursivas) si su mirada, atenta a toda innovación en la ciencia, también hubiera caído sobre el psicoanálisis... él, el gran disimulador ("Lo mejor que alcanzas a saber no puedes decirlo a los muchachos"), cuya economía del alma no fue sometida a escrutinio por el mismo Freud, sino recién por sus alumnos.

¿Y el maestro? ¿Ocupado tan solo con las interpretaciones de los poetae minores y de sus obras, la 'Richterin' de Conrad Ferdinand Meyer o la 'Gradiva' de Wilhelm Jensen? En ningún caso. No "el endeble material humano”, así 
Sigmund Freud, sino, sobre todo, los grandes artistas le llamaban la atención al intérprete, el maldito Dostoievski ante todo, del que no lograba liberarse ("Usted también está totalmente en lo cierto al suponer", le decía a Theodor Reik, "que a mí no me gusta Dostoievski, a pesar de toda mi admiración por su fuerza y nobleza. Esto se debe a que mi paciencia con los caracteres patológicos se ha agotado en mi trabajo diario" [Brief an 193]).

Pero luego Ibsen; luego -isobre todo!- las figuras de la literatura y de las artes plásticas, Moisés, Rebecca West, el rey Edipo. King Lear y, entre 1897 y 1939 vuelto a reinterpretar en siempre nuevos intentos, el príncipe Hamlet, el hijo en el ámbito de influencia del padre. Un neurótico genialisch que se negaba a realizar el doble acto edípico, asesinato e incesto, porque se acordaba de sus culpógenas visiones de infancia: Hamlet, que nunca superó su deseo infantil, sino, fracasando en el complejo de Edipo, no cumplió su obra -Hamlet, a quien su alter ego Freud le llevaba la ventaja en un punto: él sí podía analizarse después de la muerte del padre.

Resulta conmovedor ver cómo en Viena y, mucho más tarde, en Londres, figuras familiares del arte son convertidas en interlocutores -figuras del arte con los que Freud empatizaba, colocándose en su interior, con una pasión tal como si Rebecca y Hamlet fueran analizandos provenientes de Florisdorf y Kensington: seres humanos a los que les seguía la pista, fascinado por la tarea de desenterrar, descubrir su secreto. A esto se debe la descripción del Moisés furioso, caracterizada por un prolongadísimo ensimismamiento contemplativo. Dedo índice, pulgar, barba llena de nudos: el profeta es descrito con la misma intensidad como los pacientes de su consultorio, retratados con nitidez, ya sea Elisabeth o Dora; por lo mismo, los diálogos imaginarios del clínico y autoanalista con el príncipe danés que, siempre introducido como figura anexada al Edipo de Sófocles, que para Freud en realidad era lejos el más interesante, caracterizado por una nerviosidad moderna.

No cabe duda de que alguien, en la confrontación con el espíritu paterno y la madre celosamente humillada, revelaba secretos que también confesaba el analizando sobre el diván cuando, la asociación libre mediante, traspasaba aquellas barreras de la racionalidad con sus mecanismos que ocasionaban censura y represión, cuyos peligros Freud, en uno de los pasajes más esclarecedores de La interpretación de los sueños, describía no por casualidad con una referencia a un creador literario: fue Schiller quien, en una carta a Körner, señaló la necesidad de que las fuerzas creadoras harían bien en ordenar a su entendimiento de "retirar su guardia de las puertas hasta que las ideas se precipitan por ellas péle-méle" (La interpretación 124; traducción 
modificada), es decir, que no debían fomentar el sondeo precipitado, sino que recién tardíamente, luego de la intoxicación de las fantasía a través de las visiones, debían proceder a pasar revista al gran montón.

Poeta, médico y paciente en un mismo bote; literatura y contemplación de la literatura a través de un artista de categoría (en este caso Schiller) como prescripción que indica el camino para la práctica de la descomposición del alma:

Sin embargo, eso que Schiller llama "retiro de la guardia de las puertas del entendimiento", el estado de autoobservación en que se ha abolido la crítica, en modo alguno es difícil. La mayoría de mis pacientes lo consuman después de las primeras indicaciones; yo mismo puedo hacerlo a la perfección, si me ayudo escribiendo mis ocurrencias. El monto de energía psíquica que así se quita a la actividad crítica, y con el cual puede elevarse la intensidad de la observación de sí, oscila considerablemente según el tema en que se ha de fijar la atención (108).

No cabe duda de que aquí habla un escritor que bien sabía que alcanzaba la cima de la destreza artística no a través de un discurso "dogmático", sino mediante aquella consideración "genética" que lo impulsaba a colocar la ciencia al servicio de la fantasía y, con la ayuda de la fuerza de la imaginación, a sacar lo reprimido, vitalizar lo depositado y traer hacia la luz lo desaparecido en las penumbras.

Sigmund Freud era un poeta que solo de mala gana dejaba riendas sueltas a su divagar poético y justamente por esto envidiaba a los escritores literarios por su despreocupación y placer certero, ciertamente sin escatimar en "transferencias": atribuyéndole a los poetas -literalmente, a lo largo de años- lo que él mismo deseaba: poder, reputación, fama y -en primer lugarestima de parte de las mujeres. Habría sido inconcebible para el analista si un conocedor del arte le hubiera recordado que también hay escritores - un Franz Kafka, por ejemplo- para los que la escritura es una "forma de oración" y que, renunciando a toda fama posterior, comprometiendo el honor in saecula saeculorum, dispusieron la quema de su legado - ¡nada menos que El castillo y El proceso!

Freud, eso es seguro, era un admirador de los reyes de la poesía y de las celebridades (aunque fueran jugadores, figuras ambiguas y casos problemáticos en el terreno de la moral) - de los poetas en la oscuridad, en cambio, no sabía nada- nada de Hölderlin en la torre de Tübingen, nada de Georg Büchner, 
el médico y poeta, y nada, por supuesto, de Trakl y Georg Heym. Amaba a Chaplin; Arnold Zweig y Thomas Mann eran cercanos o al menos querían serlo (que en Freud, a quien no le agradaban las lisonjas, despertaba más diversión que entusiasmo: "El ensayo de Th. Mann", dice en 1929 en una carta a Lou Andreas-Salomé, luego de haber recibido el ensayo 'La posición de Freud en la historia moderna del espíritu', "por cierto es muy honroso. Causa en mí la impresión como si justo hubiera tenido preparado un ensayo sobre el romanticismo, cuando le llegó el requerimiento de escribir algo sobre mí, de modo que, como dicen los carpinteros, enchapó por delante y por detrás con psicología, este medio ensayo la masa está hecha de otra madera" [Freud y Andreas-Salomé, Briefwechsel 198f.]) Freud amaba, por sobre todos a Shakespeare y admiraba a los grandes héroes que ganarían mediante su fantasía lo que antes solo habían alcanzado en su fantasía: prestigio en todo el mundo.

Tipos temerarios, estos poetas, que, como dice en la célebre carta del 8 de mayo a Arthur Schnitzler, en cierto modo descubren lúdicamente lo que el científico dedicado al análisis recién reconoce a través de su agrio esfuerzo -las zonas de lo inconsciente con sus plantaciones de árboles jóvenes, sus cercados, sus precipicios y fauces, su estructura erótica y su oculta cara bifaz:

Estimado Señor Doctor, desde hace muchos años soy consciente de las extensas coincidencias entre sus concepciones y las mías de algunos problemas psicológicos y eróticos [...] A menudo con asombro me he preguntado de dónde usted pudo obtener este o aquel conocimiento secreto que yo he tenido que adquirir mediante investigación laboriosa del objeto y finalmente llegué a envidiar al creador literario que normalmente admiro (Briefe 266).

No era de sorprender, entonces, que Sigmund Freud, independientemente de toda distancia que en ocasiones apareciera de parte del científico respecto de los soñadores diurnos y artistas fantasiosos de la estirpe literaria (" $\mathrm{iSi}$ la toma de partido de parte de los poetas a favor de la naturaleza sensata de los sueños tan solo fuera más inequívoca!"), apuntaba a una entente cordiale entre el erudito investigador del alma y aquellos poetas que "suelen saber de una multitud de cosas entre cielo y tierra con cuya existencia ni sueña nuestra sabiduría académica" (Freud, El delirio 8). ("Y en la ciencia del alma se han adelantado grandemente a nosotros, hombres vulgares, pues se nutren de fuentes que todavía no hemos abierto para la ciencia") (8). 
Cooperación entre ciencia y arte, análisis y poesía, esa era la divisa freudiana, al menos en la fase "romántica", entre los estudios sobre la histeria y el ensayo sobre Leonardo; el poeta no debía hacerle el quite al psiquiatra y el psiquiatra no debía esquivar al poeta, sin que lo anterior implique una negación de las líneas fronterizas existentes: un científico debe tratar problemas, un poeta, de manera indirecta y a través de insinuaciones, más bien debe encubrirlos en lugar de elevarlos a la conciencia a través del nombramiento burdo de los mismos. Para Freud, la psiquiatría poética de por vida siguió siendo nonsense, una Anna $\mathrm{O}$, transportada hacia lo poético, del estatuto de una Elektra de Hofmannsthal, ni siquiera era tenida en cuenta por él: ¡zapatero a tus zapatos!

En una palabra, por muy enfáticamente que Freud insistiera en una confederación entre ciencia, artes plásticas y creación literaria (la música, más allá de su grandioso relato de una representación de 'Carmen', le era ajena), igualmente insistía en que los dos grupos que se habían presentado a golpear conjuntamente debían seguir marchando por caminos separados; dos grupos cuya meta común -primero fomentada por la poesía, luego por la psicología al modo freudiano-no era sino el esclarecimiento de mociones inconscientes del alma. De este modo, dice en 1938, en un escrito publicado de las obras póstumas, "Some Elementary lessons in Psycho-Analysis":

Hacía mucho tiempo que el concepto de lo inconsciente golpeaba a las puertas de la psicología para ser admitido. Filosofía y literatura jugaron con él harto a menudo, pero la ciencia no sabía emplearlo. El psicoanálisis se ha apoderado de este concepto, lo ha tomado en serio, lo ha llenado con un contenido nuevo (Freud, Some Elementary 288).

Aquí, un erudito le otorga a su disciplina la dignidad de una disciplina equivalente, en cuanto a su rango, la creación literaria; un psicólogo saluda a sus señores poetas (y, por supuesto, a la única Sapho) ubicados en la otra orilla - un combatiente secreto que, a pesar de su desprecio de todos los grandes y pequeños capitanes ${ }^{2}$ en los distritos de la poesía, finalmente también pertenecía al gremio del otro lado: alguien que originalmente quería llamar su estudio sobre Moisés una "novela histórica”; alguien que, según el

2 N. del traductor. El apellido de Gerhard Hauptmann, dramaturgo y escritor, el representante alemán más relevante del llamado naturalismo, autor de 'Griselda', también significa 'capitán'. 
testimonio de Stekel, en ocasiones decía que escribía novelas aprovechando sus experiencias como analista; alguien que etiquetó a su Leonardo como 'mitad ficción novelesca'; un escritor que en sus escritos 'autobiográficos', con la representación de sus sueños, brillaba como creador literario de renombre y escribía obras maestras de formato pequeño que, tomadas por ellas solas, deberían ingresar a los libros escolares como joyas maestras de la prosa alemana, desde el 'navío del desayuno' sobre los 'servicios de amor' hasta la leyenda del tejador en "Fragmento de análisis de un caso de histeria" que, si no se conoce el contexto, suena más bien como una parábola de Kafka que como un ejercicio freudiano:

Imagínese a un trabajador, por ejemplo a un albañil, que ha quedado inválido por un accidente y ahora se gana la vida mendigando en una esquina. Un taumaturgo se acerca a él y le promete sanarle la pierna inválida y devolverle la marcha. No debe esperarse, yo creo, que se pinte en su rostro una particular alegría. Sin duda alguna, se sintió en extremo desdichado cuando sufrió la mutilación, advirtió que nunca más podría trabajar y moriría de hambre o se vería forzado a vivir de la limosna. Pero desde entonces, lo que antes lo dejó sin la posibilidad de ganarse el pan se ha trasformado en la fuente de su sustento: vive de su invalidez. Si se le quita esta, quizá se lo deje totalmente inerme; entretanto ha olvidado su oficio, ha perdido sus hábitos de trabajo y se ha acostumbrado a la holgazanería, quizá también a la bebida (Fragmento de análisis 40).

Aquí se puede apreciar, a partir del placer [Freude] causado por lo 'paradojal' -como verbo- y de la diversión $[S p a \beta]$ que ocasionan las antítesis, que está basado en el atravesamiento de un proceso hasta su última pointe, aparentemente absurda, pero, en realidad, sumamente consecuente -aquí se puede ver obrar un escritor literario que con las interpretaciones de sueños se impuso la tarea más difícil que había para un artista del lenguaje en su época: la transformación de aquel 'al mismo tiempo' pictórico en un 'uno después de otro' verbal, del que habla el "Laokoon" de Lessing, y el repaso del dibujo de una fantasía que en los sueños trabaja alucinatoriamente, junto a su preferencia por lo "inadecuado, exagerado y monstruoso" [Unangemessene, Übertriebene, Ungeheurliche]. Transformar la lengua, que carece de imágenes, de lo preconsciente en una dicción que vinculaba inseparablemente la imagen poética y el terminus tecnicus trasladado desde el lenguaje coloquial hacia la ciencia especializada ("represión", "transferencia") -eso solo podía ser logrado por un maestro capaz de montar dos sillines a la vez y que, sin esfuerzo 
alguno, podía cambiar desde la asociación veloz hacia la conceptualidad detenida- una conceptualidad en la que introspecciones clínicas y metáforas osadas filtradas por el autoanálisis, alcanzaban un nuevo metanivel -más allá de la nomenclatura establecida que resulta inadecuada a la nueva enseñanza.

Desocultamiento, retiro de estratos arqueológicos, desciframiento y desvelamiento de secretos de una terra incógnita, así es como se llama la tarea autoimpuesta de Freud -una tarea que él supo resolver-al igual que Platón en La república, que San Agustín en las Confesiones -describiendo las cuevas de la memoria, del sueño y del recuerdo al interior de la fantasía en la sucesión de los grandes pensadores de la imagen que lo precedían (XXIII ${ }^{\circ}$ capítulo de las Conferencias de introducción al psicoanálisis):

La creación del reino de la fantasía dentro del alma halla su cabal correspondiente en la institución de "parques naturales", de "reservas", allí donde los reclamos de la agricultura, el comercio y la industria amenazan alterar velozmente la faz originaria de la Tierra hasta volverla irreconocible. El parque natural conserva ese antiguo estado que en todos los otros lugares se sacrificó, con pena, a la necesidad objetiva. Ahí tiene permitido pulular y crecer todo lo que quiera hacerlo, aun lo inútil, hasta lo dañino. Una reserva así, sustraída del principio de realidad, es también en el alma el reino de la fantasía (Freud Conferencias de introducción 339).

El paisaje del alma como biotopo; los recintos de la imaginación como zonas que rescatan la humanidad de la aprehensión de una realidad que se pierde cada vez más en lo anárquico: hace falta ser psicólogo y artista del lenguaje, obsesionados y poseídos, con tal de, por delante de su tiempo, poder describir coincidencias entre ámbitos de dos zonas expuestas al peligro de manera idéntica, el mundo interno y el mundo externo -y esto en un estilo que no era natural, sino, como prueban las cartas a Flie $\beta$, fue elaborado de parte de Freud con miras a aquella perfección que se muestra en la conexión entre escasez lacónica, lucidez penetrante y significancia inequívoca, de chiste e ironía, de pathos e imaginalidad dramática. El escritor Sigmund Freud, como puede leerse en sus cartas, es capaz de expresarse de manera suspendida y elegante, poética y agraciada, tal como ocurre en aquellos grandes esfuerzos epistolares (dirigidos a la novia Martha Bernays), que, esforzados por un "aumento de los adjetivos cariñosos", empiezan con "dulce amada" y que, al estilo de Fontane, luego de años de matrimonio, arriban a la confiabilidad burguesa que se expresa en un "querida vieja", el mismo Freud también 
está en condiciones de dibujar los retratos más precisos de personas reales, figuras artificiales, viviendas y ciudades, a veces en el estilo de vagancia de un Fontane, a veces paródicamente en las vestimentas de un tercero que es descrito de manera graciosa, a veces con agudeza, a veces con exuberancia, a veces imperativamente y con furia, a veces de manera relajada y permisivamente, a veces de manera lacónica, a veces divagando - pero nunca de manera aburrida, sino, en todo momento, gracioso, iluminador y de un divertimiento que termina por imponerse inevitablemente:

La simpatía de la población es muy grande. Desde ahora llueven deseos de felicidad y ramos de flores, como si de repente Su Majestad hubiera reconocido oficialmente el papel de la sexualidad, el significado del sueño hubiera sido refrendado por el Consejo de Ministros, y el Parlamento hubiera aprobado por una mayoría de 2/3 la necesidad de una terapia psicoanalítica de la histeria. Es evidente que he vuelto a ser honorable, los admiradores más tímidos me saludan en la calle a la distancia (Cartas a Fliess 503).

Sin embargo, Freud, y esto requiere ser subrayado con énfasis, no era solo un maestro de la prosa y del retrato (su Charcot en la carcasa burguesa perfectamente podría haber sido creado por Thomas Mann), sino ante todo un estratega, capaz de ordenar y de disponer historiales clínicos [Krankengeschichten] que sin sus artes de estructuración, desde la indicación de la técnica escogida y de sus problemas, pasando por el relato hacia la epicrisis, serían viñetas clínicas intercambiables [Fall-Studien] - pero no obras de arte que, producto de la exhortación de su conciencia artística, fueron desarrolladas cada vez más: obras de arte que están basadas en el intercambio de diálogo y habla indirecta, entre flujo épico e interrupción autoritaria, entre representación fabulosa e instrucción científica- siempre comenzando con lo exterior, la historia familiar y el aspecto del paciente y terminando, luego de los informes de desocultamiento que se encuentran en el centro, con una reconstrucción del caso clínico, solo presente en fragmentos, expuesto al mismo tiempo desde el punto de vista de los enfermos y del "Newton point of view" del analista.

Las monografías clínicas de Freud son ejercicios que siguen la técnica de Edipo Rey de Sófocles: el seguimiento de procesos del alma en su lento esclarecimiento hasta el conocimiento de la verdad. De esta manera, mediante el cuidado desarrollo de las fábulas y una exhibición bien calculada del escenario del acontecer con sus personajes principales y secundarios, sus caracteres de primer y segundo plano, transforma historiales clínicos en relatos 
que encuentran su lugar en antologías antes que en armarios repletos con archivos médicos. "Los historiales clínicos", así la tesis central, desarrollada en una tarde de conferencias de la Sociedad de los miércoles, el 21 de abril 1909, "nunca pueden actuar como introducciones. También hay que darle la razón a Stekel [...] en que los historiales clínicos que son comunicados de forma mutilada resultan completamente indigeribles. Como única posibilidad queda una representación concienzuda, pero 'artística' tal como en 'Dora"' (cfr. Nunberg y Federn).

Tal como en Dora: Freud tenía buenas razones para colocar justamente a este caso, su caso, por sobre todos los demás. Considerado desde aspectos poetológicos, el 'Fragmento de un análisis de histeria' no tiene igual en las obras completas freudianas, porque, a través del psicograma de una muchacha en plena pubertad, desarrolla simultáneamente un panorama victoriano general -un panorama lleno de adúlteros y gobernantes lascivas, de hombres y mujeres que, a espaldas de los afectados, firman pactos para luego quebrarlos: lleno de burgueses que hablan de moral y actúan como maquiavélicos cínicos y, esto es lo decisivo, con un narrador que -como ha mostrado el estudio de Stephen Marcus, Freud and Dora: Story, History Case History-es, al mismo tiempo, protagonista, informante y personaje principal en una misma figura; analista agudo y compañero de reparto afectado en la rueda macabra de la sociedad, un hombre que, aquí y en ningún otro lugar, indirectamente deja en claro que no quiere a su analizanda - no su severidad en el terreno sexual, no su falta de disposición a acceder a los deseos del gran mago en la cabeza del diván y definitivamente no su decisión de interrumpir el análisis y de seguir el camino sola, por su propio esfuerzo. (En todo esto hay que considerar que Freud, según su propia confesión, no logró "dominar a tiempo la transferencia" y que olvidó "tomar la precaución de estar atento a los primeros signos de la trasferencia" (Freud, Fragmento de análisis 103).

Qué drama al más puro estilo de Ibsen es este caso Dora, en el que un padre que padece una enfermedad venérea primero entrega su hija, a un buen conocido (con tal de poder mantener relaciones, sin ser estorbado y en paz, con la esposa de aquel) y que luego, cuando la muchacha se enferma de gravedad, la deja en manos del doctor Freud para que la trate -y ambos varones no se dan cuenta de que aquí una muchacha (al tiempo del tratamiento una mujer joven) se siente abandonada, expuesta, dejada a merced de otro, porque ni el padre ni el analista estaban dispuestos a tomarla en serio ni a ella ni a su visión de la realidad, porque estaban en vías de empujarla hacia un rincón, dejándola de lado; porque Freud y el padre de Dora hacían causa común 
en su mundo de varones y porque el médico evidentemente no sentía cuán insuficiente era su instrumentario analítico en un caso en el que se trataba de las mociones del alma de una niña de 14 años que, tras persianas cerradas, había sido asaltada, chantajeada, besada y humillada por justamente aquel amigo de su familia al que el padre de Dora la había puesto los cuernos. Sobre todo esto opina quien parece ser el director de la obra, pero que, en realidad, es su actor principal, Sigmund Freud: "En esta escena, la segunda en la serie pero la primera en el tiempo, la conducta de la niña de catorce años es ya totalmente histérica. Yo llamaría «histérica», sin vacilar, a toda persona, sea o no capaz de producir síntomas somáticos, en quien una ocasión de excitación sexual provoca predominante o exclusivamente sentimientos de displacer" (27).

¡Pobre Dora! Pobre muchacha que, enredada en tres vínculos afectuosos, amando quizá al Sr. K, seguramente a su padre y probablemente a la señora $\mathrm{K}$ con amor lésbico juvenil, llega a parar al tratamiento de un analista que no pudo entender que una muchacha impoluta de 14 años fracasa en una situación que, en caso de haber reaccionado "con naturalidad", "provocaría una nítida sensación de excitación sexual" (26).

Pero justamente ese no era el caso -y Freud se mostró molesto al respecto. Mientras más avanzó el análisis (solo debía durar unos pocos meses), más brusco se volvía su tono: "Usted no tiene el derecho de afirmar", "(Es decir), Usted admite que", "Usted se imaginó" -la reprimenda de parte de un juez ocupó el lugar de dirección considerada y cuidadosa. El hombre que escribió la historia aparentemente no entendió que estaba colmado de ira hacia su paciente así como lo estaba la enferma respecto de él-pero precisamente ese no saber al relato de Dora D. y Sigmund F. le otorga, de manera sumamente moderna, el carácter de una historia "abierta" que quiere ser leída a contrapelo, es decir, contra las intenciones del autor - una historia como solo pudo haber sido formulada en la época victoriana: retratar al chef de famille que es introducido como un notable burgués y que en realidad es un libertino al que, según parece, no le importa contagiar a su esposa con gonorrea- esta pobre mujer, para la que Freud, en contraste con el cálido retrato del tabético, no dispone de demasiada empatía:

De acuerdo con las comunicaciones del padre y de la muchacha, no pude menos que formarme esta idea: era una mujer de escasa cultura, pero sobre todo poco inteligente, que, tras la enfermedad de su marido y el consecuente distanciamiento, concentró todos sus intereses en la economía doméstica, y así ofrecía el cuadro de lo que 
puede llamarse "psicosis del ama de casa". Carente de comprensión para los intereses más vivaces de sus hijos, ocupaba todo el día en hacer limpiar y en mantener limpios la vivienda, los muebles y los utensilios, a extremos que casi imposibilitaban su uso y su goce. No se puede menos que incluir este estado, del cual bastante a menudo se encuentran indicios en las amas de casa normales, en la misma serie que las formas de lavado obsesivo y otras obsesiones de aseo (19).

Ninguna palabra de compasión para una mujer sexualmente humillada, engañada; ninguna condena, por muy cuidadosa que sea, del hombre del lado contrario, el que, al igual que el padre de Dora, solo quería pasarlo bien, $\mathrm{y}$, en ningún caso, un reproche a aquel protagonista que a su grandiosa historia le puso de tal manera un punto sobre las ies que ilustra lo siguiente: tampoco lo entiendo del todo, el desarrollo de aquel combate singular entre yo y una muchacha adolescente, que, con todos sus quiebres, resistencias, movimientos contrarios y ambivalencias, su dialéctica de aparecer y ser, encubrir y descubrir, he dejado por escrito con tal de sacar algo en limpio [ins Reine kommen].

Pero justamente esto se malogró -y nuestra historia que, 48 años después de su publicación, sigue siendo tan contradictoria como la revelación de la analizada a comienzos del tratamiento, que Freud acompaña con las siguientes frases, ilustra la magnitud de ese fracaso: "Este primer relato es comparable a un curso de agua atajado en parte por masas rocosas, y en parte interrumpido por bancos de arena que le quitan profundidad" (16).

De hecho, esto es lo que llamo un ejemplo paradigmático de una descripción de algo ajeno que es, en realidad, una representación de sí mismo: Sigmund Freud relata la historia de Dora y guarda silencio de que éste, quebrado en varias ocasiones y exuberante en cuanto a incongruencias no resueltas, es su propia narración, la pieza maestra de un escritor literario que, ambicioso y consecuente, pule sus estudios de casos; siempre procurando narrar lo escrito desde la distancia, de manera tal que el lector - en todo momento "a la misma altura", nunca aburrido debido a una conclusión anticipada- en ningún segundo pierda la tensión.

Work in progress, case in progress, análisis in progress se llama la máxima directriz de un narrador que solo escuchó y nunca escribió durante las sesiones, pero que, a pesar de esto, en todo momento presenta el caso como si lo descrito aconteciera ahora -en este momento-y como si el lector fuera su testigo; testigo del diálogo entre dos personas, que -a diferencia 
de toda medicina- prescinde del uso complementario de medios auxiliares y únicamente es acentuado por el instrumento más poderoso, una y otra vez celebrado por Freud de manera entusiasta: la palabra, con cuya ayuda se realiza el salto desde lo inconsciente hacia lo preconsciente; la palabra, que garantiza la conciencia; la palabra como el gran conciliador y mediador entre los seres humanos, pero que es, también, el gran elemento mágico de un efecto irrestricto:

Mediante palabras puede un hombre hacer dichoso a otro o empujarlo a la desesperación, mediante palabras el maestro trasmite su saber a los discípulos, mediante palabras el orador arrebata a la asamblea y determina sus juicios y sus resoluciones. Palabras despiertan sentimientos y son el medio universal con que los hombres se influyen unos a otros (Freud, Conferencias de introducción 15).

"Por eso, no despreciemos el empleo de las palabras en la psicoterapia" (15): así de humilde, casi casi rendido, termina el himno de un escritor que, con la excepción de Lutero, entre los escritores alemanes es el más obsesionado y poseído por la palabra -siguiendo la huella del más mínimo desplazamiento, de cada trastabillarse hablando, de cada pointe, cada chiste: a sabiendas de que únicamente a través del más exacto análisis de las palabras es posible la parsimoniosa arqueología del alma, que progresa estrato por estrato, y que la conquista de nuevos continentes para Freud tan solo pudo tener éxito cuando las asociaciones libres de los pacientes fueron contrarrestadas a través de una dación del lenguaje que enfardaba, concentraba lo disperso y estaba pendiente de la coordinación de dispar, cuyos problemas, en cada análisis, querían ser reconsiderados mediante reflexiones metodológicas introductorias.

Confieso que hasta hoy no he conseguido penetrar acabadamente la compleja ensambladura de un caso grave de neurosis obsesiva, y que en la exposición del análisis no sería capaz de evidenciar para otros, a través de las yuxtaposiciones del tratamiento, esa estructura discernida analíticamente, o vislumbrada (Observaciones sobre 128).

Si ya la recapitulación diaria de los diálogos era una tarea que hacía que Freud con frecuencia se desesperara respecto de su arte de la reproducción ("No bien reproducido, desaprovechado, difuminado mucho de la belleza propia del caso" dice en las notas del "Hombre de las ratas" [518], que ejemplifican la audacia con la que Freud, omitiendo muchos detalles significativos, estilizaba su material de análisis), si ya la abreviación de los diálogos durante 
la primera fase era lo suficientemente difícil, entonces la abstracción del proceso estilizado, la segunda y decisiva reducción en la fase de imprenta, impresionaba como una empresa endemoniada. "Se me hace difícil, este historial del "hombre de las ratas", hacía saber Freud a C. G. Jung, "casi excede mi capacidad de representación, aparte del prójimo no le será accesible a nadie. Qué chapucerías son nuestras reproducciones, cuán miserablemente deshojamos estas grandes obras de arte de la naturaleza psíquica".

Si tan solo 50 años atrás hubieran existido fonógrafos; podríamos haber sido testigos de cómo Freud, este conversador genial, analizó coram publico el caso del hombre de las ratas en un discurso libre que duró cinco horas (quiso terminar después de cuatro, pero el auditorio lo obligó a seguir hablando); podríamos ser testigos, durante una hora, y escuchar aquellos ejercicios retóricos en los que Freud convertía a su audiencia en una sociedad de neuróticos que, en sus estrechos divanes de auditorio, las incómodas butacas, requieren el consuelo y la aprobación, las palabras de ánimo y aquellos vetos alertas que también acentuaban los casos clínicos freudianos ("Bravo, pequeño Hans!", "El padre preguntaba demasiado"; "el lector tiene que adoptar una actitud crítica frente a lo anterior"). Si tan solo pudiéramos mirar en persona cuál era el efecto causado entre el público cuando el orador, en apariencia improvisando, en realidad perfectamente preparado, tomaba de la mano a su audiencia, persona por persona, con tal de -interpretando su rol preferido: el de un guía experimentado en zonas luego peligrosas, luego amigables-indicar el trayecto que ya había sido recorrido, y anticiparse interpretativamente [vorauszudeuten] a la meta que aún estaba lejos; todo esto articulado en un acto del pensamiento hablado al estilo de Lessing: “¿Lo que les digo no les resulta demasiado complicado?"; "Ahora sentirán mucha curiosidad por saber qué es lo que contiene este terrible complejo de Edipo" ("El nombre lo dice"); “¿No los confundo al revocar y restringir tantas veces lo dicho, comienzo a tejer cursos del pensar y luego los dejo caer?".

Ahí es cuando Sócrates, en un ambiente vienés, hace su ingreso a la rostra, formula objeciones, las refuta, nombra lo preliminar ("No quiero despertar convicciones - quiero dar sugerencias y socavar prejuicios") y, sobre todo, disfruta, dado que para un analista estar solo es tan aburrido, de citar ocasionalmente a opositores con los que luego se deja debatir con placer -debido a que los adversarios al final -¿cómo podría ser de otra manera?o se rinden o, derribados por la aplastante retórica freudiana, se enredan en sandeces como aquel interlocutor, introducido como un [interlocutor] 
“imparcial” en el tratado “¿Pueden los legos ejercer el análisis?” y que se entrega al juego de cambiar el rol con Freud:

No, por cierto; quedan todavía lagunas por llenar. ¿Puedo pedirle algo? ¿Quiere describirme cómo se representa usted ahora un tratamiento analítico? [...] Bueno. [...] Pero quiero darle el gusto; la responsabilidad quedará a su cargo. Bien; supongo que el enfermo acude a mí, y se queja de sus males. Le prometo curación o mejoría si obedece mis indicaciones. [...] Luego empieza a contarme y yo lo escucho. Bien; ¿y entonces? Por las comunicaciones que me hace, colijo la clase de impresiones, vivencias, mociones de deseo que ha reprimido porque le sobrevinieron en una época en que su yo era todavía endeble y les tuvo miedo, en vez de liquidarlas. Una vez que lo he puesto al corriente de ello, él se pone en las situaciones de entonces y mejora con mi ayuda. Desaparecen así las limitaciones a que su yo fue constreñido, y el enfermo sana. ¿Está bien? ¡Bravo, bravo! Veo que de nuevo me podrán reprochar que he proporcionado a un no médico la formación del analista (Pueden los legos 204).

Sócrates triunfa, el títere gracioso se queda en la estancada, la ironía ahuyenta a la petulancia, al prejuicio y a la oposición torpe, la poesía se carga a la obcecación pedante -y Sigmund Freud, un escritor que como ningún otro de sus contemporáneos cultivaba el estilo de su amado Lessing- Freud habría disfrutado su pequeña obra de arte al estilo platónico, así como habría disfrutado la galería de retratos que él si bien no creó al menos sí le sacó brillo, su disfrute de los diálogos, dignos de una obra de arte, en los estudios de caso, en los tratados y sueños: el disfrute de un hombre que era un gran escritor - un gran escritor, pero también un escritor solitario. Ningún Proust y ningún Joyce, ningún Hofmannsthal que lo haya acompañado; sí, ni siquiera, en diálogos a lo largo de los años, un Schnitzler que le haya hecho compañía. Así de solo como Freud estaba entre los que pertenecían a su gremio, así de solitario permaneció como poeta -y lo sigue estando hasta el día de hoy: ¿dónde está, nos preguntamos, el libro sobre Freud que contiene sus historias y sueños, sus aperçus y bonmots ("Aquel cuyos labios callan, se delata con las puntas de los dedos" (Fragmento 68)) y que contenga sus retratos, desde señorita Elisabeth v. R. ("Encuentro a una señora de aspecto todavía joven, con finos rasgos faciales de corte singular, yacente sobre el diván, con un almohadón de cuero bajo la nuca" [Estudios 71]), pasando por el hombre de los lobos (con su "sumisa apatía") hasta Hamlet, el hijo, sobre cuya pista, siguiendo sus huellas, Freud prosiguió incluso cuando él 
mismo, siguiendo el ejemplo de los grandes Viejos, Jacobo y Moisés, hace rato que había madurado y se había convertido en padre, -padre Freud, como lo nombró Arnold Zweig: un padre que, aún escribía con agilidad, a buen paso y elegancia (Freud consideraba que una pluma entrecortada era signo de problemas prostáticos), conservaba hasta elevada edad aquel don poético más bello que caracterizó a su juventud, el don de la improvisación y la capacidad de, a pesar de toda sobriedad, racionalidad y disciplina, toda sabiduría otorgada por la vejez y serenidad goethiana bajo el signo de la muerte, de vez en cuando retirar los guardias de las puertas de la razón y, si se ofrecía la oportunidad, en el sentido de su carta a Flie $\beta$ del 7 de julio 1898, escribir en la senda de lo inconsciente -según el célebre principio de Itzig, el jinete aficionado: "Adónde vas, Itzig? -No lo sé, ipregúntale al caballo!".

Nuestro relato de Sigmund Freud, el poeta, que comenzó con el insulto de un débil de mente antipático de nombre Hauptmann, termina con un judío y un equino: en honor a Freud, que no odiaba nada más que la aclamación y los brindis patéticos. Freud, que se caracterizaba por la sofisticación al momento de citar y de aprovechar los lemas, se encontraba más cerca de Goethe: "¿Qué sea breve! Para el día del último juicio es tan solo un pedo". Chiste emparejado con sabiduría, ambos unidos en provocador sentido de las profundidades: ¡salud por Sigmund Freud, el poeta!

\section{BIBLIOGRAFÍA}

Freud, Sigmund. "Conferencias de introducción al psicoanálisis". Obras Completas, vol. XV y XVI. Buenos Aires: Amorrortu (1916-17 [1915-17])/1900.

“¿Pueden los legos ejercer el análisis? Diálogos con un juez imparcial”. Obras Completas, vol. XX (165-234). Buenos Aires: Amorrortu, 1926/1989.

“A propósito de un caso de neurosis obsesiva”. Obras Completas, vol. X (119-249). Buenos Aires: Amorrortu, 1909/1989.

“Algunas lecciones elementales sobre psicoanálisis". Obras Completas, vol. XXIV (279-288). Buenos Aires: Amorrortu, 1940 [1938]/1989.

"Brief an Theodor Reik" (14.4.1929). Gesammelte Werke, Nachtragsband, Frankfurt a. M.: Fischer, 1930b/1970.

Cartas a Wilhelm Fließ. 1887-1904. Buenos Aires: Amorrortu, 1994.

"El delirio y los sueños en la «Gradiva» de W. Jensen". Obras completas, vol. IX

(1-80), Buenos Aires: Amorrortu, 1907/1989.

"Fragmento de análisis de un caso de histeria". Obras Completas, vol. VII (1-223).

Buenos Aires: Amorrortu, 1905/1989. 
"La interpretación de los sueños". Obras Completas, vol. IV y V. Buenos Aires: Amorrortu, 1900 [1899]/1989.

"Originalnotizen zu einem Fall von Zwangsneurose". Gesammelte Werke, Nachtragsband (509-569). Frankfurt a. M.: Fischer, 1950/1970.

"Premio Goethe". Obras Completas, vol. XXI (203-206). Buenos Aires: Amorrortu, 1930/1989.

Freud, Sigmund y Andreas-Salomé, Lou. Briefwechsel. Frankfurt a. M.: Fischer, 1966.

Gauger, Hans-Martin. "Sprache und Sprechen im Werk Sigmund Freuds". Neue Rundschau, 85 (1974): 568-569.

Jappe, Gemma. Über Wort und Sprache in der Psychoanalyse. Frankfurt a. M.: Fischer, 1971.

Mahoney, Patrick. Freud als Schriftsteller. Frankfurt a. M.: Suhrkamp, 1981/1989.

Marcus, Steven. "Freud and Dora. Story, history, case study". Freud and the Culture of Psychoanalysis. Boston: Allen \& Unwin, 1984.

Musch, Walter. "Freud als Schriftsteller". Die Zerstörung der deutschen Literatur (303-347). Zürich: Diogenes, 1930/2009.

Nunberg, Herman y Ernst Federn (eds.). Protokolle der Wiener Psychoanalytischen Vereinigung. Tomo I: 1908-1910. Frankfurt a. M.: Fischer, 1967/1977.

Pörsken, Uwe. "Die Terminologie der Psychoanalyse". Deutsche Naturwisssenschaftssprachen (150-181). Tübingen: Narr, 1973/1986.

Schönau, Walter. Sigmund Freud. Literarische Elemente seines Stils. Stutgart: Klett, 1968.

Spector, Jack J. Freud und die Ästhetik. Psychoanalyse, Literatur und Kunst. München: Kindler, 1972/1973.

Urban, Bernd. Hofmannsthal, Freud und die Psychoanalyse. Frankfurt, Bern, Las Vegas: Lang, 1978.

Worbs, Michael. Nervenkunst. Literatur und Psychoanalyse im Wien der Jahrhundertwende. Frankfurt a. M.: EVA, 1983. 